\title{
Low-Dose Prasugrel in Patients with Resistance to Clopidogrel for the Treatment of Cerebral Aneurysms
}

\author{
Dongwhane Lee, $\mathrm{MD}^{1}$, Yunsun Song, $\mathrm{MD}^{1}$, Minkyu Han, $\mathrm{PhD}^{2}$, Danbi Park, $\mathrm{MS}^{1}$, \\ Dae Chul Suh, MD, PhD ${ }^{1}$ \\ ${ }^{1}$ Department of Radiology, Asan Medical Center, University of Ulsan College of Medicine, Seoul, Korea \\ ${ }^{2}$ Department of Clinical Epidemiology and Biostatistics, Asan Medical Center, University of Ulsan College of Medicine, Seoul, Korea
}

\begin{abstract}
Thromboembolism is one of the major complications of stent assisted coiling in treatment of cerebral aneurysm. Clopidogrel resistance is so common and prasugrel is more effective in its rapid and potent effect. We investigated changes in the value of P2Y12 resistance unit (PRU) when prasugrel was administered to patients with clopidogrel resistance. One hundred mg of aspirin and $75 \mathrm{mg}$ of clopidogrel were administered for 5 days before the procedure, and PRU were examined. The resistance to clopidogrel was defined as the inhibition of PRU was less than 20\%. PRU was re-examined after loading $20 \mathrm{mg}$ of prasugrel. We treated 98 consecutive patients between January 2018 and July 2018, and 24 patients (24.5\%) had resistance to clopidogrel. Nineteen patients were female. The mean PRU value at admission was $238.5 \pm 36.9$ and the percentage inhibition value was $4.8 \pm 6.3 \%$. After the use of prasugrel, the mean PRU and percentage inhibition values were measured as $124.9 \pm 49.9$ and $48.0 \pm 19.24$, respectively. All patients except one patient had a PRU inhibition value as a responder. There was no hemorrhage or thromboembolic complication during mean 1.5 months follow-up after embolization procedure. In conclusion, in patients resistant to clopidogrel, the low dose prasugrel seems to be effective in keeping the percentage inhibition value of PRU within the normal range in treatment of cerebral aneurysm. Further study will be needed to determine the optimal dose of prasugrel to enhance prevention effect of thromboembolism and to reduce hemorrhagic complications during stent assisted coiling.
\end{abstract}

Key Words: Prasugrel hydrochloride; Clopidogrel; Platelet aggregation inhibitors; Drug resistance; Intracranial aneurysm

\section{INTRODUCTION}

Thromboembolism is a major complication of stent-assisted coiling for the treatment of a cerebral aneurysm. Clopidogrel (Bristol-Myers Squibb, New York, NY, USA) has been used with aspirin (Bayer, Leverkusen, Germany) for stent-assisted coiling in the treatment of cerebral aneurysms. However, the cyto- chrome P450 (CYP) 2 C19 polymorphism associated with clopidogrel resistance is so common that it appears in more than $55 \%$ of East Asian populations. ${ }^{2}$ Among homozygous alleles of clopidogrel resistance caused by the loss of function of CYP2C19, clopidogrel cannot inhibit the activity of platelets even after loading an additional dose. ${ }^{3}$ Prasugrel (Eli Lilly, Indianapolis, IN, USA) is a third-generation

\author{
Correspondence to: \\ Dae Chul Suh, MD, PhD \\ Department of Radiology, Asan Medi- \\ cal Center, University of Ulsan College \\ of Medicine, 88, Olympic-ro 43-gil, \\ Songpa-gu, Seoul 05505, Korea \\ Tel: +82-2-3010-4366 \\ Fax: +82-2-3010-0090 \\ E-mail:dcsuh@amc.seoul.kr
}

Received: August 21, 2018

Revised: August 24, 2018 Accepted: August 24, 2018

Copyright $\odot 2018$ Korean Society of Interventional Neuroradiology This is an Open Access article distributed under the terms of the Creative Commons Attribution Non-Commercial License (http://creativecommons.org/licenses/by-nc/3.0) which permits unrestricted non-commercial use, distribution, and reproduction in any medium, provided the original work is properly cited.

PISSN 2093-9043 eISSN 2233-6273 
orally-active P2Y12 inhibitor that is also converted to an active metabolite by the CYP system. ${ }^{4}$ It is more effective than clopidogrel in its rapid onset of efficacy and potent inhibitory effect on platelet aggregation. There have been studies using prasugrel in the treatment of cerebral aneurysms with stent-assisted coils, but no studies have been performed on only patients with clopidogrel resistance..$^{5-8}$ In addition, there is no definite guideline for patients with low-body weight, as in Koreans for whom prasugrel was not allowed, probably due to the risk of bleeding. Thus, we aimed to investigate changes in the value of $\mathrm{P} 2 \mathrm{Y} 12$ resistance unit (PRU) when prasugrel was administered to patients with clopidogrel resistance.

\section{MATERIALS AND METHODS}

In the treatment of an intracranial aneurysm, from 6 days before the procedure, $100 \mathrm{mg}$ of aspirin and $75 \mathrm{mg}$ of clopidogrel were administered for 5 days. Aspirin reaction unit and PRU were examined at 11:00 A.M. the day before the procedure using the VerifyNow assay (Accumetrics, San Diego, CA, USA). PRU and percentage inhibition values were measured to evaluate platelet reactivity. The reactivity of platelet function to P2Y12 inhibitors was divided into three categories: "non-responder" (less than 10\%), "hypo-responder" (10-20\%), and responder (over 20\%). ${ }^{9}$ The resistance to clopidogrel was defined as an inhibition of PRU less than 20\%. In this case, PRU was re-examined at 8:00 A.M. on the day of the procedure using $5 \mathrm{mg}$ as a maintenance dose after loading 20 $\mathrm{mg}$ of prasugrel from the day before the procedure. Patients with a history of transient ischemic attack (TIA) or ischemic stroke were excluded. ${ }^{10}$ We also collected information pertaining to patient demographics including height and body weight, risk factors, past medical history, and laboratory findings. Clinical follow-up was made after the embolization procedure.

\section{RESULTS}

We treated 98 consecutive patients with an aneurysm between January 2018 and July 2018, and 24 patients (24.5\%) had resistance to clopidogrel. The median age was 61 years, and 19 patients (79.1\%) were female (Table 1). The median body weight and body mass index was $50.5 \mathrm{~kg}$ and $23.8 \mathrm{~kg} / \mathrm{m}^{2}$, respectively. All aneurysms were unruptured. Four patients had two or more aneurysms. Thirteen patients (54.2\%) had small (3-5 $\mathrm{mm})$ aneurysms, and all aneurysms were confined to the anterior circulation. Intracranial stents were used in 18 patients (75.0\%). The mean PRU value at admission was $238.5 \pm 36.9$, and the percentage inhibition value was $4.8 \pm 6.3 \%$. Thirteen patients (54.2\%) had a percentage inhibition value of $0 \%$. After the use of prasugrel, the mean PRU and percentage inhibition values were measured as $124.9 \pm 49.9$ and $48.0 \pm 19.24$, respectively. All patients except one patient had a PRU inhibition value as a responder. There was no hemorrhage or thromboembolic complication during a mean follow-up of 1.5 months (range, 1-7) after the embolization procedure.

Table 1. Characteristics of patients treated with prasugrel

\begin{tabular}{|c|c|}
\hline & Value $(n=24)$ \\
\hline Age (years) & $61.0(54.5-66.8)$ \\
\hline Female sex & $19(79.1)$ \\
\hline Body weight (kg) & $57.7(56.1-62.5)$ \\
\hline Body mass index $\left(\mathrm{kg} / \mathrm{m}^{2}\right)$ & $23.8(22.6-25.3)$ \\
\hline Hypertension & $9(37.5)$ \\
\hline Diabetes & $4(16.7)$ \\
\hline Hyperlipidemia & $5(20.8)$ \\
\hline Previous use of antiplatelet agent & $2(8.3)$ \\
\hline ARU & $453.5 \pm 72.9$ \\
\hline PRU (initial) & $238.5 \pm 36.9$ \\
\hline Percentage inhibition (initial) & $4.8 \pm 6.25$ \\
\hline Non-responder (initial) & $17(70.8)$ \\
\hline Hypo-responder (initial) & $7(29.2)$ \\
\hline Responder (initial) & 0 \\
\hline PRU (after use of prasugrel) & $124.9 \pm 49.9$ \\
\hline Percentage inhibition (after use of prasugrel) & $48.0 \pm 19.24$ \\
\hline Non-responder (after) & $1(4.2)$ \\
\hline Hypo-responder (after) & 0 \\
\hline Responder (after) & $24(95.8)$ \\
\hline Multiple aneurysms in procedure & $4(16.7)$ \\
\hline Use of stent & $18(75.0)$ \\
\hline $\begin{array}{l}\text { Neuroform atlas (Stryker Neurovascular, } \\
\text { Fremont, CA, USA) }\end{array}$ & $17(94.4)$ \\
\hline LVIS blue (MicroVention, Tustin, CA, USA) & $1(5.6)$ \\
\hline
\end{tabular}

Values are presented as mean \pm standard deviation, medians (with quartiles), or number (\%).

ARU, aspirin reaction unit; PRU, P2Y12 reaction unit. 


\section{DISCUSSION}

When prasugrel was administered in patients with resistance to clopidorel, the percentage inhibition values of PRU were within the effective range for most patients (95.8\%). Only two of these patients had a percentage inhibition value of more than 70 in PRU, and both were over $60 \mathrm{~kg}$. In addition, even those with relatively low-body weights were found to have reached the effective range when low doses of prasugrel were given.

The most frequently reported genetic polymorphism in the use of clopidogrel is increased mortality from myocardial infarction, stroke, and vascular disease, and it is particularly likely to cause thrombosis after stenting. ${ }^{2}$ In comparison, prasugrel has a fast and potent antiplatelet effect; it also maintains an almost 80\% platelet inhibitory effect at 2 hours after administration and maintains its effect continuously. ${ }^{4}$ However, the use of prasugrel for cerebrovascular disease is still debated, as it involves the problem of intracranial bleeding. "1 Since prasugrel has been used for acute myocardial infarction, it also has indications for stent-assisted coiling for reimbursement from the Korean Ministry of Food and Drug Safety. ${ }^{12}$

Unlike Westerners, however, Asians are known to weigh less and have a higher incidence of cerebral hemorrhage. ${ }^{13}$ In fact, only 14\% of the participants in the TRITRON-TIMI 38 study who have proven to have hemorrhagic complications from prasugrel were from the Middle East, Africa, or Asia-Pacific region, suggesting that it is difficult to generalize to Asian people. ${ }^{10}$ In fact, there was no difference in bleeding complications with clopidogrel in randomized controlled trial for acute coronary syndrome in Japan where a low dose of prasugrel (20/3.75 mg, loading/maintenance dose) was used. .4 $^{14}$

In contrast to acute coronary syndrome, stent-assisted coiling is not generally required for lifelong therapy of antiplatelet agents, so low-dose prasugrel for short-term use may be effective. However, as reported in previous large-scale studies, it is advisable to consider reducing the dose for patients older than 75 years or for patients weighing less than $60 \mathrm{~kg}$ and avoiding use in patients with a history of stroke or TIA. ${ }^{10}$ It should be noted, however, that in other studies, the value of PRU itself was used instead of percentage inhibition values, unlike in our study, because PRU values were considered more important. ${ }^{15}$

Our study has some limitations. This study was a sin- gle-arm retrospective study, and no long-term follow-up was performed. Also, it is difficult to investigate an independent predictor because there were a small number of participants. In conclusion, in patients resistant to clopidogrel, low-dose prasugrel seems to be effective in keeping the percentage inhibition value of PRU within the normal range in treatment of a cerebral aneurysm. Further study will be needed to determine the optimal dose of prasugrel to enhance the prevention effect against thromboembolism and to reduce hemorrhagic complications during stent-assisted coiling.

\section{Acknowledgments}

This work was supported by the National Research Foundation of Korea (NRF) grant funded by the Korea government (MSIT) (No. 2018R1A2B6003143).

\section{REFERENCES}

1. Chalouhi N, Jabbour P, Singhal S, Drueding R, Starke RM, Dalyai RT, et al. Stent-assisted coiling of intracranial aneurysms: predictors of complications, recanalization, and outcome in 508 cases. Stroke 2013:44:1348-1353

2. Mega JL, Close SL, Wiviott SD, Shen L, Hockett RD, Brandt JT, Walker, et al. Cytochrome p-450 polymorphisms and response to clopidogrel. N Engl J Med 2009;360:354-362

3. Mega JL, Hochholzer W, Frelinger AL 3rd, Kluk MJ, Angiolillo DJ, Kereiakes DJ, et al. Dosing clopidogrel based on CYP2C19 genotype and the effect on platelet reactivity in patients with stable cardiovascular disease. JAMA 2011;306:2221-2228

4. Niitsu Y, Jakubowski JA, Sugidachi A, Asai F. Pharmacology of CS-747 (prasugrel, LY640315), a novel, potent antiplatelet agent with in vivo P2Y12 receptor antagonist activity. Semin Thromb Hemost 2005;31:184-194

5. Choi HH, Lee JJ, Cho YD, Han MH, Cho WS, Kim JE, et al. Antiplatelet premedication for stent-assisted coil embolization of intracranial aneurysms: low-dose prasugrel vs clopidogrel. [published online ahead of print Dec 29, 2017] Neurosurgery 2017

6. Sedat J, Chau Y, Gaudart J, Sachet M, Beuil S, Lonjon M. Prasugrel versus clopidogrel in stent-assisted coil embolization of unruptured intracranial aneurysms. Interv Neuroradiol 2017;23:5259

7. Ha EJ, Cho WS, Kim JE, Cho YD, Choi HH, Kim T, et al. Prophylactic antiplatelet medication in endovascular treatment of intracranial aneurysms: low-dose prasugrel versus clopidogrel. AJNR 
Am J Neuroradiol 2016;37:2060-2065

8. Cho WS. Lee J, Ha EJ, Kim KH, Lee J, Cho YD, et al. Low-dose prasugrel versus clopidogrel-based tailored premedication for endovascular treatment of cerebral aneurysms. [published online ahead of print Aug 20, 2018] Neurosurgery 2018

9. Tantry US, Bliden KP, Gurbel PA. Resistance to antiplatelet drugs: current status and future research. Expert Opin Pharmacother 2005;6:2027-2045

10. Wiviott SD, Braunwald E, McCabe CH, Montalescot G, Ruzyllo W, Gottlieb S, et al. Prasugrel versus clopidogrel in patients with acute coronary syndromes. N Engl J Med 2007;357:2001-2015

11. Akbari SH, Reynolds MR, Kadkhodayan Y, Cross DT 3rd, Moran CJ. Hemorrhagic complications after prasugrel (Effient) therapy for vascular neurointerventional procedures. J Neurointerv Surg 2013;5:337-343
12. National Institute of Food and Drug Safety Evaluation. Instruction to change permission. http://www.nifds.go.kr/brd/m_86/ view.do?seq=27549. Accessed August 19, 2018

13. An SJ, Kim TJ, Yoon BW. Epidemiology, risk factors, and clinical features of intracerebral hemorrhage: an update. J Stroke 2017;19:3-10

14. Isshiki T, Kimura T, Ogawa H, Yokoi H, Nanto S, Takayama M, et al. Prasugrel, a third-generation P2Y12 receptor antagonist, in patients with coronary artery disease undergoing elective percutaneous coronary intervention. Circ J 2014;78:2926-2934

15. Kang HS, Kwon BJ, Kim JE, Han MH. Preinterventional clopidogrel response variability for coil embolization of intracranial aneurysms: clinical implications. AJNR Am J Neuroradiol 2010;31:1206-1210 